\title{
Prediction of Wellbore Temperatures During the Scientific Ultra-deep Drilling Process
}

\author{
Fanhe Meng, Aiguo Yao* and Shuwei Dong
}

Faculty of Engineering, China University of Geosciences, Wuhan, Hubei, 430074, China

\begin{abstract}
In order to carry out a series of key basic researches, a scientific ultra-deep drilling plan is being undertaken in China. Wellbore temperature is one of the key factors during the drilling process. In this paper, we established a twodimensional transient numerical model to predict the ultra-deep wellbore temperature distributions during circulation and shut-in stages. The simulation results indicate that the cooling effort of drilling fluid circulation is very obvious, especially during the inception phase. Drilling fluid viscosity has great influence on the temperature distributions during circulation stage: the lower the viscosity, the higher the bottom hole temperature. While drilling fluid displacement and inlet temperature have a little effort on the bottom hole temperature. During the shut-in stage, the wellbore temperature recovery is a slow process.
\end{abstract}

Keywords: Scientific drilling, ultra-deep well, transient temperature, finite difference method.

\section{INTRODUCTION}

Continental scientific drilling is a direct technique to reveal the composition and structure of the continental crust, verify the results of geophysical explorations. It can also provide information on the Earth's natural resources, the global climate and environmental changes and the processes causing earthquakes. It is acknowledged as "a telescope entering the interior of the Earth" [1]. Therefore, many countries have carried out the deep exploration program since 1970s [2]. In the former Soviet Union, 11 ultra deep wells were drilled and the famous one is the $12260 \mathrm{~m}$ depth Kola SG 3 ultra deep well, which is the world's deepest one of all time. KTB-which stands for German Continental Deep Drilling Program completed a $4000.1 \mathrm{~m}$ pilot hole and a $9101 \mathrm{~m}$ main hole in 1990s, through which lots of achievements have been obtained [3]. In China, building on the success of the Chinese Continental Scientific Drilling Project (CCSD), a national scientific program titled as "Deep Exploration Technology and Experimentation" (ab. as SinoProbe) has been implemented since 2008. As part of the project, ultradeep drilling technology $(>10000 \mathrm{~m})$ will be developed based on pilot drilling and experimental work.

During the ultra-deep drilling process, the downhole high-temperature problem is not inevitable. With a geothermal gradient of $3^{\circ} \mathrm{C} / 100 \mathrm{~m}$, the $10000 \mathrm{~m}$ downhole temperature can reach about $300^{\circ} \mathrm{C}$. But KTB's experience shows that drilling fluid circulation can strongly influence the wellbore temperatures [4]. However, these dynamic temperature distributions are very important since they can be used in the following activities: drilling fluid rheology, cementing pro-

*Address correspondence to this author at the Faculty of Engineering, China University of Geosciences, Wuhan, 430074, China;

Tel: 0086-027-67884253; E-mail: a.yao@cug.edu.cn gram design, wellbore and casing stability evaluation, downhole tool selection, etc. Therefore, how to predict the transient wellbore temperatures during the drilling process becomes a key problem.

In 1941, Farris developed many charts for depicting the bottomhole temperature during cementing periods [5]. Then, based on the field measurements of Farris, the American Petroleum Institute (API) developed new empirical correlations for estimating circulating temperatures for cementing. But some research has observed that the API method always overestimates circulating fluid temperatures for deep wells [6]. Besides, this method is originally developed for the oil drilling industry, which differs notably from scientific drilling technology. To solve this problem, two approaches have been emerged to estimate the wellbore temperatures: analytical and numerical. The classical analytical method was developed by Ramey [7], which assumed that heat transfer in the well bore is steady state, while heat transfer in the formation is unsteady radial conduction. In general, this method is applicable to system geometries of lesser complexity, such as the case of a single casing string and single temperature gradient. While the numerical method can tackle more complex problems which involves solving the governing heat transfer equations numerically using a finite difference scheme. Raymond proposed the first numerical model for predicting wellbore temperatures during drilling fluid or cement circulation [8]. Keller et al. extended Raymond's method. In their model, the presence of multiple casing strings and energy sources were included [9]. Wooley developed the first transient computer program-GEOTEMP for prediction of bottomhole temperature [10]. Beirute developed a simulator for estimation of temperatures during circulation and shut-in stage [11]. The altemating-directionimplicit method was used to obtain the solutions. The comparison of the simulation results with field data provided 


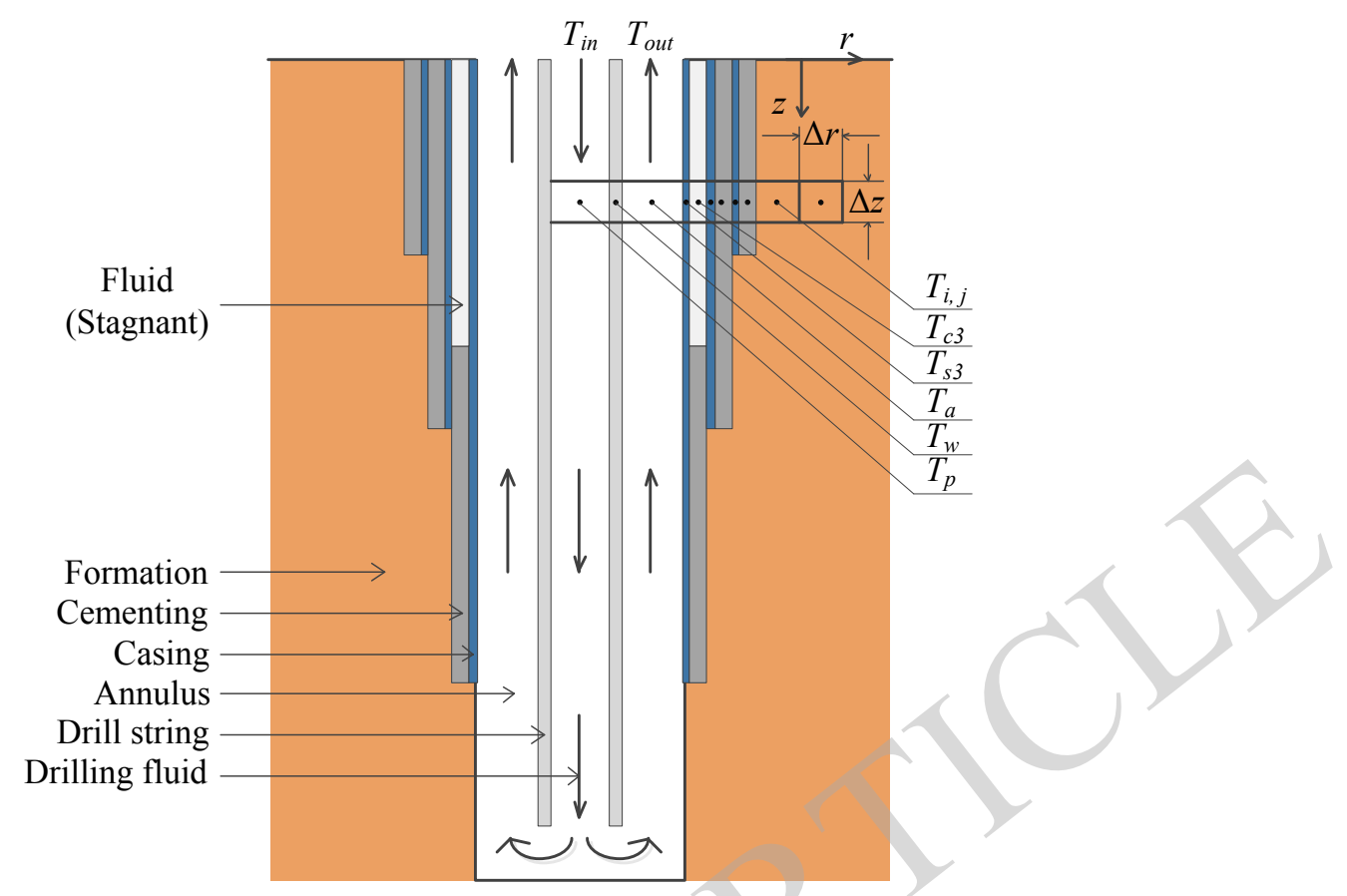

Fig. (1). Physical model of drilling fluid circulation.

good agreement. GARCIA et al. developed the program TEMLOPI v1.0 for predicting temperatures in and around geothermal wells [12]. And then they proposed the method of estimating wellbore temperatures under lost circulation conditions [13]. Osisanya and Harris established a twodimensional and fully transient model to prediction of wellbore temperatures and the solution was obtained by CrankNicolson method [14].

With the features of accurate, reliable and economic, numerical simulators are considered to be the best method to predict the transient temperature distributions in scientific ultra-deep wells. However, seldom research has been emphasized in this area before. The transient heat transfer model need to be established in order to predict wellbore temperatures during the whole drilling process.

\section{PHYSICAL MODEL}

During the scientific drilling process, the stage can be mainly divided into two ones: circulation and shut-in. The circulation stage can be basically described in three main phases: drilling fluid flows down the drill string, through the bit, and up to the surface (Fig. 1).

In different stages and phases, the downhole temperatures depend on the different heat transfer processes. In general, the formation temperature increases with depth. Therefore, the temperature of drilling fluid always increases during the flowing down process. The heated drilling fluid flows up to the surface, and exchanges heat with the surrounding materials and formation. This system acts very much like a counter-flow heat exchanger. However, during the shut-in stage, the wellbore system (fluids, casing, cement and formation) gradually reaches the thermal equilibrium mainly by heat conduction.

\section{FUNDAMENTAL ASSUMPTIONS}

To derive the energy equations for describing the overall thermal behaviour of the wellbore system, certain assumptions need to be considered.

1. The scientific drilling is almost vertical. And it is assumed to be an axisymmetric problem.

2. Drilling fluid is incompressible and no fluid losses to the formation.

3. Heat transfer for the drilling fluid is only by convection, since axial and radial conduction has little effect on wellbore temperature distributions [15].

4. Ignoring the influence of adaptors on the wellbore geometry.

5. No phase change occurs.

\section{MODEL DEVELOPMENT}

As the different heat transfer mechanisms, the circulation and shut-in stages need to be treated differently. With respect to the overall circulation process, five heat transfer regions can be identified: (a) the drill pipe; (b) the drill pipe wall; (c) the annulus; (d) the wellbore wall; and (e) the surrounding formation. For shut-in stage, only axial and radial conduction was considered. Based on the energy conservation law, a set of governing equations were developed.

\subsection{Circulation Stage}

\subsubsection{Drill Pipe Model}

For a control volume inside the pipe, heat flows in by convective of the fluid column, convection with the inner 
drill pipe wall and the fluid fraction energy source. Therefore, the model can be expressed as equation (1), where the righthand term represents the accumulation of energy.

$Q_{p}-\rho_{m} q c_{m} \frac{\partial T_{p}}{\partial z}+2 \pi r_{p i} h_{p i}\left(T_{w}-T_{p}\right)=\rho_{m} c_{m} \pi r_{p i}^{2} \frac{\partial T_{p}}{\partial t}$

where $Q_{p}$ is the energy source term of unit length inside the drill pipe; $\rho_{m}$ and $c_{m}$ are the density and heat capacity of drilling fluid, respectively; $q$ is the flow rate; $T_{p}$ and $T_{w}$ are the temperatures of inside drill pipe fluid and drill pipe wall, respectively; $z$ is the length in wellbore direction; $r_{p i}$ is the inner radius of drill pipe; $h_{p i}$ is the convection coefficient of inside drill pipe wall; and $t$ is the time.

\subsubsection{Drill Pipe Wall Model}

The heat transfer model of drill pipe wall can be expressed as equation (2). The first left term respects the vertical conduction in the drill pipe. And the last two ones respect the convection between the drill pipe and the fluid inside and outside the string.

$\lambda_{w} \frac{\partial^{2} T_{w}}{\partial z^{2}}+\frac{2 r_{p o} h_{p o}}{r_{p o}^{2}-r_{p i}^{2}}\left(T_{a}-T_{w}\right)-\frac{2 r_{p i} h_{p i}}{r_{p o}^{2}-r_{p i}^{2}}\left(T_{w}-T_{p}\right)$

$=\rho_{w} c_{w} \frac{\partial T_{w}}{\partial t}$

where $\lambda_{w}, \rho_{w}$ and $c_{w}$ are the thermal conductivity, density and heat capacity of drill pipe, respectively; $r_{p o}$ is the outer radius of drill pipe; $h_{p o}$ is the convection coefficient of outer drill pipe wall; and $T_{a}$ is the temperature of annulus fluid.

\subsubsection{Annular Model}

To calculate the temperature distribution of annulus, the main heat transfer mechanisms need to be considered, including: (a) heat generated by fluid fraction and drill string rotation; (b) heat convection up the annulus; (c) radial convection between the annulus fluid and the surrounding drill string and formation. Therefore, the model is expressed as follows.

$$
\begin{aligned}
& Q_{a}+\rho_{m} q c_{m} \frac{\partial T_{a}}{\partial z}+2 \pi r_{a} h_{b}\left(T_{b}-T_{a}\right)-2 \pi r_{p o} h_{p o}\left(T_{a}-T_{w}\right) \\
& =\rho_{m} c_{m} \pi\left(r_{a}^{2}-r_{p o}^{2}\right) \frac{\partial T_{a}}{\partial t}
\end{aligned}
$$

where $Q_{a}$ is the energy source term of unit length inside the annulus; $r_{a}$ is the radius of wellbore wall; $h_{b}$ is the convection coefficient of wellbore wall; and $T_{b}$ is the temperature of the interface between annulus and borehole wall.

\subsubsection{Wellbore Wall Model}

The axial conduction and internal energy change can be neglected for a sufficiently small control volume of wellbore wall. Based on the energy balance, heat transfers by radial conduction and convection should be equal. Therefore, the following equation is derived.

$\lambda_{f}\left(\frac{\partial T_{f}}{\partial r}\right)_{r=r_{a}}=h_{b}\left[T_{f}\left(r_{a}, z\right)-T_{a}\right]$

where $\lambda_{f}$ is the thermal conductivity of formation; $r$ is the radial distance from wellbore; and $T_{f}$ is the temperature of formation.

\subsubsection{Formation Model}

According to casing program, the formation region could be casing strings, cement or rock formations. The twodimensional heat conduction model in cylindrical coordinate system can be used to calculate the temperature distributions in this region. The model is written as follows.

$$
\frac{\partial^{2} T_{f}}{\partial z^{2}}+\frac{\partial^{2} T_{f}}{\partial r^{2}}+\frac{1}{r} \frac{\partial T_{f}}{\partial r}=\frac{\rho_{f} \mathcal{C}_{f}}{\lambda_{f}} \frac{\partial T_{f}}{\partial t}
$$

where $\rho_{f}$ and $c_{f}$ are the density and heat capacity of formation, respectively.

\subsection{Shut-in Stage}

For shut-in conditions, the two-dimensional heat conduction model in cylindrical coordinates can also be adopted during the thermal recovery process. The temperature distributions are governed by the equation.

$$
\frac{\partial^{2} T_{x}}{\partial z^{2}}+\frac{\partial^{2} T_{x}}{\partial r^{2}}+\frac{1}{r} \frac{\partial T_{x}}{\partial r}=\frac{\rho_{x} c_{x}}{\lambda_{x}} \frac{\partial T_{x}}{\partial t}
$$

where the subscript $x$ represents the different regions.

\subsection{Initial and Boundary Conditions}

To solve the above governing equations, the proper initial and boundary conditions should be derived. For circulation stage, the undisturbed static temperatures can be used as the initial condition. In mathematical language they are expressed as:

$T_{x}(z, t=0)=T_{s}+G z$

where $T_{s}$ is the surface formation temperature; and $G$ is the geothermal gradient.

As the inlet fluid temperature can be measured, the boundary condition for the drill fluid can be written as equation (8).

$T_{p}(z=0, t)=T_{\text {in }}$ 
Table 1. Casing program.

\begin{tabular}{|c|c|c|c|c|c|}
\hline Parameter & First Cement & First Casing & Second Casing & Third Cement & Third Casing \\
\hline \hline Outer diameter (mm) & 712 & 622 & 406 & 382 & 346 \\
\hline Inner diameter (mm) & 622 & 596 & 382 & 346 & 314 \\
\hline Depth (m) & $0 \sim 300$ & $0 \sim 300$ & $0 \sim 3000$ & $4300 \sim 6000$ & $0 \sim 6000$ \\
\hline
\end{tabular}

Table 2. Thermophysical properties.

\begin{tabular}{|c|c|c|c|}
\hline Component & Density $(\mathbf{K g} / \mathbf{m} 3)$ & $\begin{array}{c}\text { Specific Heat Hapacity } \\
\left(\mathbf{J} /\left(\mathbf{k g} \cdot{ }^{\circ} \mathbf{C}\right)\right)\end{array}$ & $\begin{array}{c}\text { Thermal Conductivity } \\
\left(\mathbf{W} /\left(\mathbf{m} \cdot{ }^{\circ} \mathbf{C}\right)\right)\end{array}$ \\
\hline \hline Drilling fluid & 1050 & 4164 & 0.608 \\
\hline Casing & 7850 & 469 & 43.33 \\
\hline Cement & 2400 & 757 & 0.639 \\
\hline Formation & 2300 & 840 & 2.25 \\
\hline
\end{tabular}

where $T_{\text {in }}$ is the drilling fluid inlet temperature.

The boundary conditions for the formation can be described as: the temperatures are constant at formation surface, far away from the wellbore, and a sufficient distance below the wellbore.

$T_{f}(z=0, r, t)=T_{s}$

$T_{f}(z, r \rightarrow \infty, t)=T_{s}+G z$

$T_{f}(z=H+\Delta z, r, t)=T_{s}+G(H+\Delta z)$

where $H$ is the total vertical depth of the well.

For shut-in stage, the initial temperature distributions decided by the circulation history. The boundary condition equation (9) still applies in this condition.

\section{NUMERICAL SOLUTION}

For numerically solving the heat transfer model, the twodimensional space was divided into finite vertical and radial elements. For each element, the governing equations are written. And then these partial differential equations were solved by the finite difference method (FDM). The implicit form was used since it is unconditionally stable. Although a serious of algebraic equations can be obtained after the model discretized, a single generalized vector form can be obtained for equations of each region, expressed as:

$\mathrm{A}_{\mathrm{i}, \mathrm{j}} T_{i-1, j}^{n}+\mathrm{B}_{\mathrm{i}, \mathrm{j}} T_{i, j}^{n}+\mathrm{C}_{\mathrm{i}, \mathrm{j}} T_{i+1, j}^{n}=\mathrm{D}_{\mathrm{i}, \mathrm{j}}$

where subscripts $i$ and $j$ correspond to the depth coordinate and radial coordinate respectively; superscript $n$ represents the time level; A, B, C are the coefficient matrixs; and D is the matrix of the constants.
Then a Matlab program was established to calculate these tridiagonal matrix systems. With this simulator, the next time level temperatures of each region can be calculated in sequence using the previous iteration results, until the error range can be accepted.

\section{CASE STUDY}

\subsection{Simulation Parameters}

In order to validate the proposed model and evaluate the effect of operating parameters on temperature distributions, a $7000 \mathrm{~m}$ scientific deep well was simulated. The casing program is shown in Fig. (1), and the geometry data is detailed in Table 1.

The undisturbed bottomhole temperature is $200^{\circ} \mathrm{C}$. The volume flow rate of drilling fluid was assumed constant at $0.03 \mathrm{~m}^{3} / \mathrm{s}$, with a surface inlet temperature of $25^{\circ} \mathrm{C}$. The water-based drilling fluid viscosity is $0.03 \mathrm{~Pa} \cdot \mathrm{s}$. The required thermophysical properties are detailed in Table 2.

\subsection{Results}

The effect of circulation time on the bottomhole fluid temperature is shown in Fig. (2). As can be seen, drilling fluid circulation has a great influence on the wellbore temperatures, especially during the 2 hours after circulation starting, just as the KTB's experience. The bottomhole fluid temperature drops from $200^{\circ} \mathrm{C}$ to $135^{\circ} \mathrm{C}$ quickly. However, with the circulation time increases, the influence becomes gradually weakened. After 4 hours of circulation, the bottomhole fluid temperature almost no longer changes. This phenomenon has great significance for the operation of downhole instruments during the scientific ultra-deep drilling process. In this case, the instruments can be lowered after 


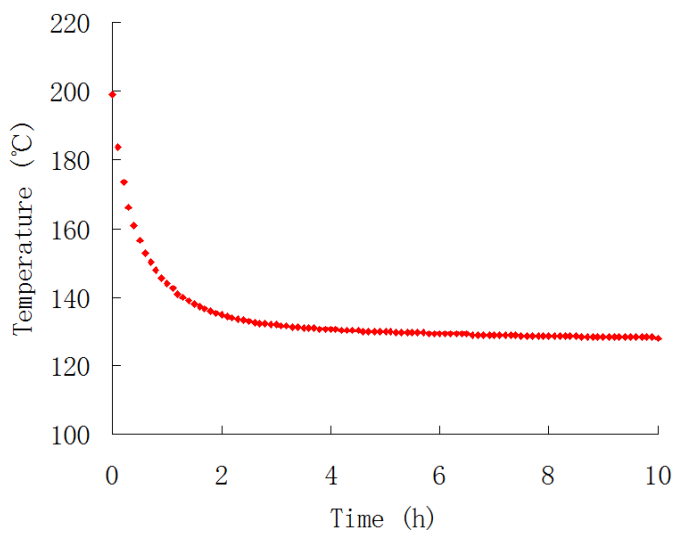

Fig. (2). Effect of circulation time on the bottomhole fluid temperature.

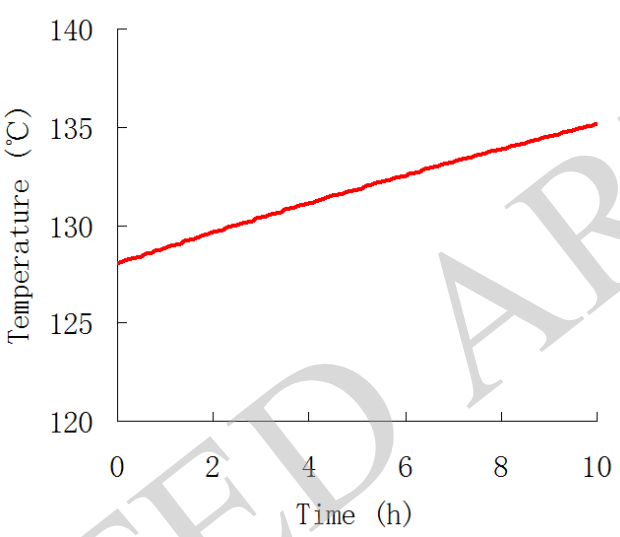

Fig. (3). Effect of shut-in time on the bottomhole fluid temperature.

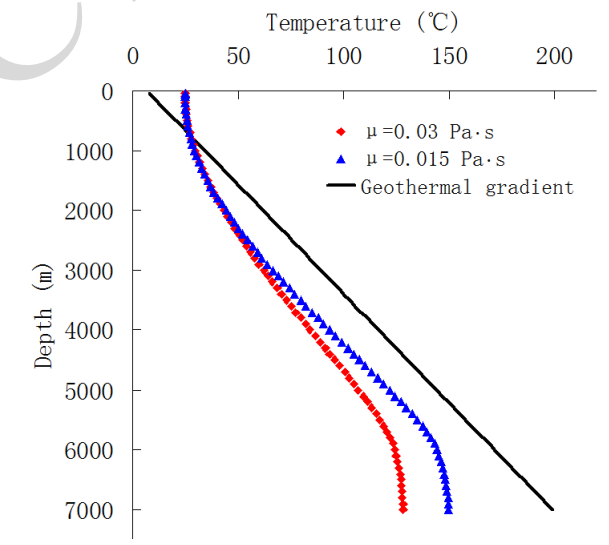

Fig. (4). Effect of drilling fluid viscosity on the wellbore temperature Field.

a period of circulation or keep circulating during lowered to ensure the safety.

As logging and cementing operated soon after the circulation stopped, the thermal recovery during shut-in stage is also very important. Assumed that the initial condition of shut-in stage is the temperature distribution after 10 hours of circulation, the temperature recovery of the bottomhole fluid is shown in Fig. (3). The thermal recovery is a slow process because conduction is the only way for heat transfer and the thermal conductivity of formation is relatively small. After 10 hours of shut-in, the bottomhole fluid temperature gradually increases from $128^{\circ} \mathrm{C}$ to $135^{\circ} \mathrm{C}$.

To find out the importance of drilling fluid viscosity, simulation work was conducted with only viscosity was allowed to change while all others held constant. The result is shown in Fig. (4). By data analysis, maximum differences of 


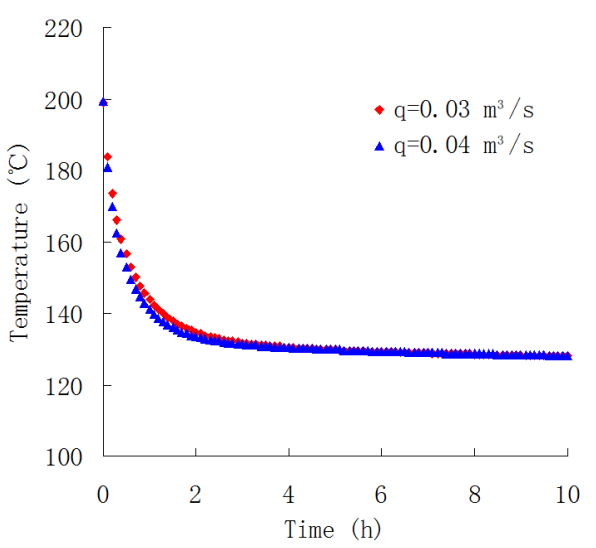

Fig. (5). Effect of drilling fluid displacement on the bottomhole fluid temperature.

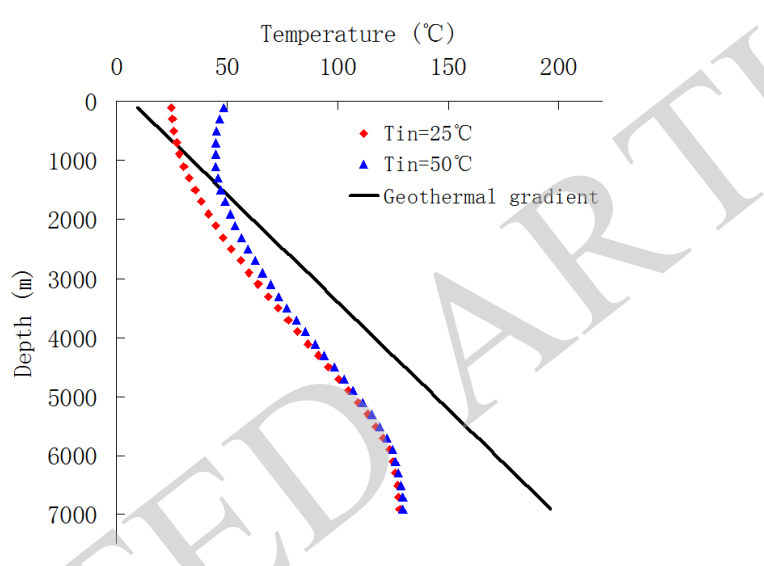

Fig. (6). Effect of drilling fluid Inlet temperature on the wellbore temperature field.

about $21.6^{\circ} \mathrm{C}$ are found at the bottom of the well after 10 hours of circulation. These temperature differences indicate that the viscosity of drilling fluid strongly influences the wellbore temperature distributions. These differences are directly due to the convection coefficient which is a function of viscosity. Generally, the fluid viscosity decreases, the heat transfer coefficient increases. Under the circulation conditions, the higher convective coefficient tends to increase the heat exchange between the fluid and the formation. In addition, the influence of downhole conditions need to be considered if the drilling fluid viscosity changes with temperature or pressure greatly.

The effect of drilling fluid displacement on the bottomhole fluid temperature is shown in Fig. (5). During the initial phase, the higher fluid displacement leads to the lower bottomhole temperature. This is mainly duo to cooling effect of fluid circulation. More heat can be transferred form downhole to surface if the fluid displacement is higher. After a period of circulation, the bottomhole fluid temperature begins to stabilize and the influence of displacement becomes weakened. During the scientific ultra-deep drilling process, the effect of higher fluid displacement can be used to cool down the bottomhole, but the working conditions, such as pump performance and borehole wall stability, should also be considered.
The effect of drilling fluid inlet temperature on the wellbore temperature field is shown in Fig. (6). As can be seen, the differences of these two temperature profiles get smaller with the depth increase after 10 hours of circulation. Moreover, the lower part of these temperature profiles are almost the same. Therefore, the cooling effect of inlet fluid temperature on bottomhole is not obvious during the scientific ultradeep drilling process.

\section{CONCLUSION}

A two-dimensional and fully transient numerical model has been established to predict the wellbore temperatures during the whole scientific ultra-deep drilling process. Based on the finite difference method, a simulator has been developed. By simulating analysis, the following conclusions can be drawn.

1. The drilling fluid circulation strongly affects the wellbore temperature distributions. The cooling effect of circulation is obvious during the inception phase. After a period of circulation, the bottomhole fluid temperature almost no longer changes.

2. The disturbed wellbore temperature distributions caused by circulation can not be easily recovered. The thermal recovery is a slow process during shut-in stage. 
3. The drilling fluid viscosity has a significant effect upon the bottomhole wellbore temperature under circulation conditions. The lower the viscosity, the higher the bottomhole temperature.

4. The drilling fluid displacement can affect the temperature distributions only at the inception phase of circulation. The higher displacement has a faster cooling effect at the bottom.

5. The inlet drilling fluid temperature partially affects the wellbore temperature profiles. And the upper part is more easily influenced than others.

\section{CONFLICT OF INTEREST}

The authors confirm that this article content has no conflict of interest.

\section{ACKNOWLEDGEMENTS}

Declared none.

\section{REFERENCES}

J. S. Yang, Z. Q. Xu, and Z. L. Tang, "Continental scientific drilling: site selection and pilot holes," Acta. Geoscientica. Sin., vol. 32, pp. 84-112, 2011.

[2] S. W. Dong, T. D. Li, R. Gao, and Q. T. Lv, "International progress in probing the earth's lithosphere and deep interior: a review," Acta. Geological. Sin., vol. 84, no. 6, pp. 743-770, 2010.

[3] R. Emmermann, and J. Lauterjung, "The German continental deep drilling program KTB: overview and major results," J. Geophys. Res., vol. 102, no. B8, pp. 18179-18201, 1997.
[4] H. Wilhelm, "Undisturbed temperature in the main drillhole of the German Continental Deep Drilling Program predicted from temperature logs recorded after shut-in," Geothermics, vol. 29, no. 3, pp. 393-406, 2000.

[5] R. F. Farris, "A practical evaluation of cements for oil wells," Drilling and Production Practice, API-41-283, 1941.

[6] Z. M. Chen, and R. J. Novotny, "Accurate prediction wellbore transient temperature profile under multiple temperature gradients: finite difference approach and case history," SPE84583, 2003.

[7] H. J. Ramey, "Wellbore heat transmission," J. Pet. Technol., vol. 14 , no. 4, pp. 427-435, 1962.

[8] L. R. Raymond, "Temperature distribution in a circulating drilling fluid," J. Pet. Technol., vol. 21, no. 3, pp. 333-341, 1969.

[9] H. H. Keller, E. J. Couch, and P. M. Berry, "Temperature distribution in circulating mud columns," Soc. Pet. Eng. J., vol. 13, no. 1, pp. 23-30, 1973.

[10] G. R. Wooley, "Computing downhole temperatures in circulation injection and production wells," J. Pet. Technol., vol. 32, no. 9, pp. $1509-1522,1980$.

[11] R. M. Beirute, "A circulating and shut-in well-temperature-profile simulator," J. Pet. Technol., vol. 43, no. 9, pp. 1140-1146, 1991.

[12] A. Garcia, I. Hernandez and G. Espinosa, "TEMLOPI: a thermal simulator for estimation of drilling mud and formation temperatures during drilling of geothermal wells," Comput. Geosci., vol. 24, no. 5, pp. 465-477, 1998.

[13] Garcia, E. Santoyo, and G. Espinosa, "Estimation of temperatures in geothermal wells during circulation and shut-in in the presence of lost circulation," Transp. Porous Media, vol. 33, pp. 103-127, 1998.

[14] O. O. Harris, and S. O. Osisanya, "Evaluation of equivalent circulating density of drilling fluids under high pressure/high temperature conditions," SPE97018, 2005.

[15] M. Yang, Y. F. Meng, and G. Li, "Effects of the radial temperature gradient and axial conduction of drilling fluid on the wellbore temperature distribution," Acta. Phys. Sin., vol. 62, no. 7, p. 079101, 2013.

Received on: May 26, 2015

Revised on: July 14, 2015

Accepted on: August 10, 2015

(C) Meng et al.; Licensee Bentham Open.

This is an open access article licensed under the terms of the (https://creativecommons.org/licenses/by/4.0/legalcode), which permits unrestricted, non-commercial use, distribution and reproduction in any medium, provided the work is properly cited. 